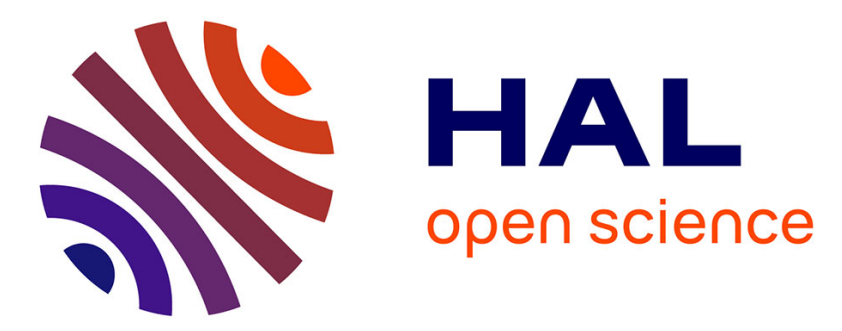

\title{
Economics of technological games among telecommunication service providers
}

Patrick Maillé, Bruno Tuffin, Jean-Marc Vigne

\section{To cite this version:}

Patrick Maillé, Bruno Tuffin, Jean-Marc Vigne. Economics of technological games among telecommunication service providers. Globecom 2010: Global Communications onference, Dec 2010, Miami, United States. hal-00609530

\section{HAL Id: hal-00609530 \\ https://hal.science/hal-00609530}

Submitted on 19 Jul 2011

HAL is a multi-disciplinary open access archive for the deposit and dissemination of scientific research documents, whether they are published or not. The documents may come from teaching and research institutions in France or abroad, or from public or private research centers.
L'archive ouverte pluridisciplinaire HAL, est destinée au dépôt et à la diffusion de documents scientifiques de niveau recherche, publiés ou non, émanant des établissements d'enseignement et de recherche français ou étrangers, des laboratoires publics ou privés. 


\section{Economics of Technological Games Among Telecommunication Service Providers}

\author{
Patrick Maillé \\ Institut Telecom; Telecom Bretagne \\ 2, rue de la Châtaigneraie CS 17607 \\ 35576 Cesson Sévigné Cedex, France \\ Email: patrick.maille@telecom-bretagne.eu
}

\author{
Bruno Tuffin \\ INRIA Rennes - Bretagne Atlantique \\ Campus Universitaire de Beaulieu \\ 35042 Rennes Cedex, France \\ Email: Bruno.Tuffin@inria.fr
}

\author{
Jean-Marc Vigne \\ Institut Telecom; Telecom Bretagne \\ 2, rue de la Châtaigneraie CS 17607 \\ 35576 Cesson Sévigné Cedex, France \\ Email: jm.vigne@telecom-bretagne.eu
}

\begin{abstract}
The telecommunication world keeps evolving, with the development of new technologies, and operators have to wonder if investing in the costly infrastructures and potential licenses as well as maintaining existing technologies is worthy. This has to be investigated in a competitive context. We propose in this paper to model and analyze a three-level game between two operators. At the highest level operators decide which technology to implement, possibilities being here 3G, WiFi and WiMAX. At the intermediate level, they fix their service price, while at the lowest level, customers choose their provider depending on price and quality of service. The model is analyzed by backward induction, where decisions at a level depend on the equilibria at the lower levels. Different real-life cost scenarios are studied, depending on whether or not operators already own the infrastructures and licenses: our model should help understanding their final decision.
\end{abstract}

\section{INTRODUCTION}

Competition among telecommunication providers is fierce. Providers do not only compete for customers by playing on their price and offered quality of service (QoS) but, due to the so-called convergence with terminals supporting multiple interfaces, they also have to choose which technology to operate. That issue is of increasing interest with the introduction of new interfaces and the possibility to get a license, such as currently with WiMAX [1] or LTE. The questions an operator should then ask itself are the following: is it worth paying a license and an infrastructure for being present in the new technology? Will it help to attract more customers, but then isn't it at the expense of other technologies already implemented? This has to be decided given the current positions (and forecasted decisions) of competitors, which also aim at maximizing their revenue. Another typical illustration comes from the third generation wireless licenses in France where the regulator wants to open a fourth license to increase competition. Candidates have to ponder the total cost with the revenue they will get from customers. This paper aims at helping with such decisions, not only for the operator but additionally for the regulator to define the appropriate license fees.

The model we present is made of three levels, corresponding to three different time scales. At the lowest level, given fixed operated technologies and service costs, customers spread themselves among available operators in order to get the "best" combination of price and QoS, where the QoS (or the congestion) they get depends on the choice of the other users. We assume that users are infinitesimal, so that the (selfish) decision of a single individual does not have any influence on the system behavior. The equilibrium analysis is therefore provided by the so-called Wardrop's principle [2]. This equilibrium is for fixed prices, but providers determine beforehand (by backward induction) what the resulting equilibrium (and therefore their revenue) would be for a given price profile, and play the corresponding pricing game accordingly. This constitutes the second level of game, the general framework being again that of non-cooperative game theory, and the equilibrium notion, the Nash equilibrium [3], with atomic players here. Finally, at a larger time scale, providers can decide which technologies to operate. In order to make that decision, they have to compute what their revenue would be at the equilibrium or equilibria (if any) of the lower-level pricing game, and compare it with their costs. That choice, which also depends on the strategy of competitors, will be made in order to reach again a Nash equilibrium for this "technology game".

While users' distribution among providers and pricing games have been quite extensively studied [4], [5], [6], [7], [8], [9], there is to our knowledge no other paper dealing with the technology game, especially using the result of the pricing game. Other multilevel games exists, the most notable one being [10], but it rather models the interactions between Internet service providers and content providers. Our goal is here to answer the question about which technology a provider should implement, given the potential revenue and the potential infrastructure and license costs. We have not seen elsewhere this kind of study in a similar competitive context. We also provide typical and real-life competition situations of providers already installed but which could try to extend their technological range to increase their revenue.

The paper is organized as follows. In Section II, we describe the mathematical model and three levels of game for its analysis. Section III describes the user game, characterizing the (Wardrop) equilibrium. Section IV is devoted to the intermediate game on prices. it considers an average coverage zone and reviews the capacities for the different wireless technologies. Based on those numbers, the revenues at the equilibrium of the pricing game are displayed for each combination of technologies implemented by the providers. 
Section V relates those revenues with implementation costs representative of real-life competition among provider. This leads to a technological game that is solved and analyzed for each considered specific scenario.

\section{MODEL}

Consider $N$ providers in competition for customers (later on, we will take $N=2$, but we keep the model description as general as possible). Each provider has to decide which set of technologies it will operate. There is a set $\mathcal{T}$ of available technologies, basically for us

$$
\mathcal{T}=\{3 \mathrm{G}, \text { WiMAX, WiFi }\} .
$$

This set is partitionned into two subsets $\mathcal{T}_{p}$ and $\mathcal{T}_{s}$ : for the technologies in $\mathcal{T}_{p}(=\{3 \mathrm{G}$, WiMAX $\})$, each operating provider owns a license and a part of the radio spectrum, using it alone. On the other hand, for a technology in $\mathcal{T}_{s}$ $\left(\mathcal{T}_{s}=\{\mathrm{WiFi}\}\right.$ for us), the spectrum is shared by the customers of the competing providers. Define also $\mathcal{S}_{i}$ as the set of technologies operated by $i$.

We assume that each provider $i(1 \leq i \leq N)$ prespecifies a price $p_{i}$ per unit of flow that a customers needs to pay if using its network. This price $p_{i}$ is the same whatever the technology used by customers at provider $i$. We also assume that users have terminals with multiple interfaces, allowing them to use any technology, and that they can sense the available QoS. As a consequence, they can choose the technology and provider offering the best combination of price and QoS.

Formally, let $d_{i, t}$ be the flow demand experienced at technology $t$ by provider $i$, and $\mathbf{d}$ the vector of all flow demands. QoS is modeled by a congestion function $\ell_{i, t}\left(d_{i, t}\right)$ for technology $t \in \mathcal{T}_{p}$ operated by provider $i$, and $\ell_{t}\left(\sum_{j} d_{j, t}\right)$ for $t \in \mathcal{T}_{s}$, functions being assumed nonnegative, continuous and strictly increasing in terms of the total. Customers try to minimize their perceived price at technology $t$ and provider $i$, defined by

$$
\bar{p}_{i, t}(\mathbf{d})=\left\{\begin{aligned}
p_{i}+\ell_{i, t}\left(d_{i, t}\right) & \text { if } \quad t \in \mathcal{T}_{p} \\
p_{i}+\ell_{t}\left(\sum_{j} d_{j, t}\right) & \text { if } \quad t \in \mathcal{T}_{s} .
\end{aligned}\right.
$$

This means that the perceived price is a linear combination of a monetary cost (the price charged) and a QoS cost (the congestion level). This model extends the one proposed in [4], since here different technologies can be operated by a single provider, and some can also be shared.

We also assume that total user demand is a continuous function $D(\cdot)$ of the perceived price $\bar{p}$, strictly decreasing continuous on its support and differentiable, with $\lim _{p \rightarrow \infty} D(p)=0$.

The system is characterized by by three different time scales:

- at the shortest scale, for fixed prices and sets of offered technologies, users choose their provider and technology in order to minimize their perceived price. Customers are assume non-atomic. This leads to a user equilibrium situation $\left(d_{i, t}^{*}\right)_{i, t}$ following the Wardrop's principle, where for all technologies with positive demand, the perceived price is the same, other technologies have higher larger perceived prices (otherwise some users would have an interest to change to a cheaper option).

- At the intermediate time scale, providers compete for customers by playing with prices for fixed sets of implemented technologies. The goal of each provider $i$ is to maximize its revenue

$$
R_{i}=\sum_{t \in \mathcal{S}_{i}} p_{i} d_{i, t}^{*},
$$

playing on price $p_{i}$ and making use of what the user equilibrium $\mathbf{d}^{*}=\left(d_{i, t}^{*}\right)_{i, t}$ would be for a given price profile. Since the revenue of a provider depends on the price strategy of competitors (through the user equilibrium), this is analyzed using non-cooperative game theory.

- At the larger time scale, providers have to chose which technologies to invest on. This is again analyzed thanks to non-cooperative game theory, using the equilibrium situation $\left(p_{i}^{*}\right)_{1 \leq i \leq N}$ of the intermediate level.The goal is here again to optimize

$$
R_{i}=\sum_{t \in \mathcal{S}_{i}} p_{i}^{*} d_{i, t}^{*}-c_{i, t}
$$

(where $c_{i, t}$ represents the license and infrastructure costs to provider $i$ to operate on technology $t$ ), by playing with the set $\mathcal{S}_{i}$.

\section{THE USER LEVEL}

The outcome of the interactions among nonatomic users should follow Wardrop's principle [2]: only cheapest options are chosen, and total demand corresponds to that cheapest price. Formally, given a technology configuration $S=$ $\left(S_{1}, \ldots, S_{N}\right)$ and a price configuration $\left(p_{1}, \ldots, p_{N}\right)$, a Wardrop equilibrium is a tuple $\left(d_{1,1} \ldots, d_{N,\left|S_{N}\right|}\right)$ of positive real numbers such that

$$
\left\{\begin{array}{r}
\forall i \in \mathcal{N}, \forall t \in \mathcal{S}_{i} \quad \bar{p}_{i, t}=\left\{\begin{array}{r}
p_{i}+\ell_{i, t}\left(d_{i, t}^{*}\right) \quad \text { if } \quad t \in \mathcal{T}_{p} \\
p_{i}+\ell_{t}\left(\sum_{j: t \in \mathcal{S}_{j}} d_{j, t}^{*}\right) \quad \text { if } \quad t \in \mathcal{T}_{s}
\end{array}\right. \\
\forall i \in \mathcal{N}, \forall t \in \mathcal{S}_{i} \quad d_{i, t}^{*}>0 \Longrightarrow \bar{p}_{i, t}=\min _{j \in \mathcal{N}, \tau \in \mathcal{S}_{j}}\left(\bar{p}_{j, \tau}\right) \\
\sum_{i \in \mathcal{N}} \sum_{t \in \mathcal{S}_{i}} d_{i, t}^{*}=D\left(\min _{i \in \mathcal{N}, t \in \mathcal{S}_{i}}\left(\bar{p}_{i, t}\right)\right)
\end{array}\right.
$$

The first equality gives the perceived price for each pair (operator, technology), the second one states that users choose the cheapest options, and the last one comes from the demandprice relation.

The nonatomic game that is played among users falls into the widely-studied set of routing games [11], [12], [13]. Indeed, the user problem can be interpreted as finding a route (i.e., a pair provider-technology) to reach the global internet, while congestion effects occur. Several powerful results exist for that kind of games, that we apply to prove existence and uniqueness of a user equilibrium for our particular problem. 
Proposition 1: There always exists a user equilibrium. Moreover, the corresponding perceived price at each providertechnology pair $(i, t)$ is unique.

Proof: Since all congestion functions are strictly increasing and demand at price 0 is strictly positive, then at an equilibrium all perceived prices are strictly positive. Then the existence of a Wardrop equilibrium directly comes from Theorem 5.4 in [12] (just a few extra verifications are needed for the specific - and unrealistic - case where some providers set their price to 0 ).

For a Wardrop equilibrium, we denote by $\bar{p}$ the common perceived price of all options (i.e., pairs provider-technology) that get positive demand. Assume there exist two Wardrop equilibria $\mathbf{d}$ and $\hat{\mathbf{d}}$ with different perceived prices, say $\bar{p}$ and $\hat{\bar{p}}$, and assume without loss of generality that $\bar{p}>\hat{\bar{p}}$. Since the demand function is strictly decreasing on its support, then total demand for $\mathbf{d}$ is strictly smaller than for $\hat{\mathbf{d}}$. This means that either total demand on one of the shared technologies, or demand on one proprietary technology of a provider, is strictly smaller for $\mathbf{d}$ than for $\hat{\mathbf{d}}$. But following Wardrop's principle, this would mean that the corresponding cost for that technology is the minimal cost $\hat{\bar{p}}$ for $\hat{\mathbf{d}}$, that is strictly larger (due to congestion cost increasingness) than for $\mathbf{d}$, itself being larger than $\bar{p}$, a contradiction. As a result, the perceived price $\bar{p}$ for options with demand is unique, and we necessarily have for each provider-technology pair $(i, t)$ :

$$
\begin{aligned}
& t \in \mathcal{T}_{p} \quad \Rightarrow \quad \bar{p}_{i, t}=\max \left(\bar{p}, p_{i}+\ell_{i, t}(0)\right) \\
& t \in \mathcal{T}_{s} \Rightarrow \bar{p}_{i, t}=p_{i}+\max \left(\bar{p}-\underline{p}_{t}, \ell_{t}(0)\right),
\end{aligned}
$$

where $\underline{p}_{t}=\min \left\{p_{i}, t \in S_{i}\right\}$. All perceived prices are unique, which concludes the proof.

\section{THE PRICING GAME}

In this section, we propose to analyze the pricing game in the case of two providers whatever the subset of technologies in $\{3 \mathrm{G}$, WiMAX, WiFi $\}$ each of them implements. Providers aim at maximizing their revenue.

We assume that a set of users is positioned in a predefined zone and that all users have a terminal with multiple interfaces. We have in mind a specific zone covered by a 3G UMTS base station in France (composed of about $10^{4}$ such zones). We additionally assume that the zone is covered by a WiFi $802.11 \mathrm{~g}$ access point and a single 802.16e (WiMAX) base station. In our numerical application, we will choose realistic values of demand and capacities, and will only consider downlink for convenience. The realistic capacity values we consider are

- $28 \mathrm{Mb} / \mathrm{s}$ per operator for 3G [14];

- $40 \mathrm{Mb} / \mathrm{s}$, still in downlink, for WiMAX technology [15];

- $25 \mathrm{Mb} / \mathrm{s}$ for WiFi [16].

We moreover assume the demand function $D$ to be linear, given by (in $\mathrm{Mb} / \mathrm{s}$ )

$$
D(\bar{p})=300-3 \bar{p},
$$

with $\bar{p}$ in $€ /$ month. Hence no user is willing to pay more than $100 €$ monthly to benefit from the service. In our numerical

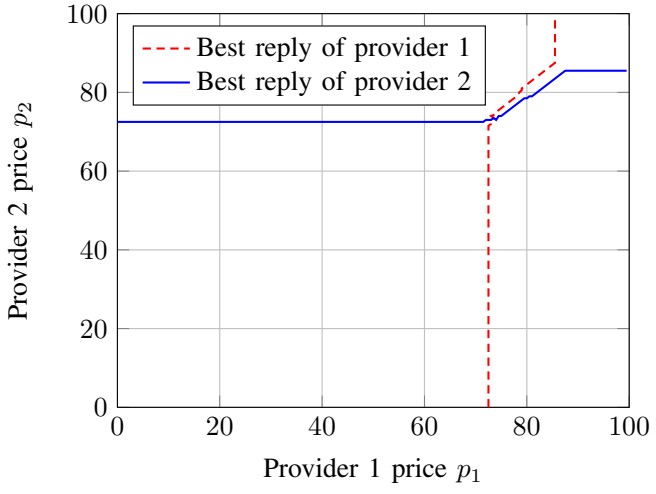

Fig. 1. Curves of best prices if both players propose the WiMax technology

computations, the congestion function $\ell_{i, t}$ of a couple demandtechnology $(i, t)$ is supposed to be the average waiting time of a $\mathrm{M} / \mathrm{M} / 1$ queue of parameters $\left(d_{i, t}, C_{i, t}\right)$ if the technology $t$ belongs to the set $\mathcal{T}_{p}$, and of parameters $\left(\sum_{t \in \mathcal{S}_{i}} d_{i, t}, C_{t}\right)$ if $t$ belongs to $\mathcal{T}_{s}$. Recall that the average waiting time of an $\mathrm{M} / \mathrm{M} / 1$ queue with parameters $(\lambda, \mu)$ is $1 /(\mu-\lambda)-1 / \mu$.

Using those parameters, we investigate numerically for each couple of technology sets $\left(\mathcal{S}_{1}, \mathcal{S}_{2}\right)$ the existence of a Nash equilibrium on the price war. Recall too that a Nash equilibrium is a price profile $\left(p_{1}^{*}, p_{2}^{*}\right)$ such that $\forall p_{1}, p_{2} \geq 0$ $R_{1}\left(p_{1}^{*}, p_{2}^{*}\right) \geq R_{1}\left(p_{1}, p_{2}^{*}\right)$ and $R_{2}\left(p_{1}^{*}, p_{2}^{*}\right) \geq R_{2}\left(p_{1}^{*}, p_{2}\right)$. In words, no provider can improve its revenue by deviating unilaterally. In our numerical computations, we have always found that for any technology profile where shared technologies are operated by only one provider, there exists a unique non-null Nash equilibrium. However, proving analytically the existence and uniqueness of such a Nash equilibrium would deserve more work. To illustrate how those Nash equilibria are found, consider for instance the case where the two operators decide to propose only a WiMAX access to the users. Figure 1 displays the best responses (i.e., prices maximizing their revenue) of providers in terms of the price of the other. A Nash equilibrium is an intersection point of those two curves.

One can check that there exists a single non-null intersection point between the two curves, here approximately equal to $(72.5,72.5)$.

Table I displays the monthly revenues in euros of operators at the (non-null, if any) Nash price profile, for every technology profile. It is noticeable that the revenue is null for the two operators in a configuration in which they both choose the WiFi technology. This observation can be interpreted intuitively: if both providers implement $\mathrm{WiFi}$, consider a nonnull price profile. For a provider, it is always worthy to price just below the competitor to attract all the WiFi users and then increase its revenue. But this is also valid for the competitor, so that we end up with a price profile $(0,0)$.

\section{ILlustrative technological Games}

In the previous section, we have seen how, whatever the set of technologies implemented by the providers, an equilibrium can be reached in the pricing game, with revenues from 


\begin{tabular}{|c|c|c|c|c|c|c|c|c|}
\hline $1 \mathrm{~V}$ & $\emptyset$ & $3 \mathrm{G}$ & WiMAX & 3G,WiMAX & WiFi & WiFi,3G & WiFi,WiMAX & WiFi,3G,WiMAX \\
\hline$\emptyset$ & $0 ; 0$ & $0 ; 2470$ & $0 ; 3379$ & $0 ; 5081$ & $0 ; 2228$ & $0 ; 4220$ & $0 ; 4921$ & $0 ; \mathbf{6 1 9 3}$ \\
\hline 3G & $2470 ; 0$ & $2200 ; 2220$ & $2090 ; 3022$ & $1843 ; 4506$ & $2241 ; 1985$ & $1970 ; 3752$ & $1859 ; 4367$ & $1623 ; \mathbf{5 4 1 5}$ \\
\hline WiMAX & $3379 ; 0$ & $3022 ; 2090$ & $2864 ; 2864$ & $2489 ; 4240$ & $3061 ; 1887$ & $2689 ; 3545$ & $2532 ; 4112$ & $2192 ; \mathbf{5 0 4 3}$ \\
\hline 3G,WiMAX & $5081 ; 0$ & $4506 ; 1843$ & $4240 ; 2489$ & $3638 ; 3638$ & $\mathbf{4 5 7 2} ; 1666$ & $\mathbf{3 9 5 7} ; 3079$ & $\mathbf{3 6 9 1} ; 3538$ & $\mathbf{3 0 9 2} ; \mathbf{4 2 3 2}$ \\
\hline WiFi & $2228 ; 0$ & $1985 ; 2241$ & $1887 ; 3061$ & $1666 ; \mathbf{4 5 7 2}$ & $0 ; 0$ & $0 ; 0$ & $0 ; 0$ & $0 ; 0$ \\
\hline WiFi,3G & $4220 ; 0$ & $3752 ; 1970$ & $3545 ; 2689$ & $3079 ; 3957$ & $0 ; 0$ & $0 ; 0$ & $0 ; 0$ & $0 ; 0$ \\
\hline WiFi,WiMAX & $4921 ; 0$ & $4367 ; 1859$ & $4112 ; 2532$ & $3538 ; 3691$ & $0 ; 0$ & $0 ; 0$ & $0 ; 0$ & $0 ; 0$ \\
\hline WiFi,3G,WiMAX & $\mathbf{6 1 9 3} ; 0$ & $\mathbf{5 4 1 5} ; 1623$ & $\mathbf{5 0 4 3} ; 2192$ & $\mathbf{4 2 3 2 ; 3 0 9 2}$ & $0 ; 0$ & $0 ; 0$ & $0 ; 0$ & $0 ; 0$ \\
\hline
\end{tabular}

TABLE I

REVENUES MATRIX (FROM USERS) FOR PROVIDERS DEPENDING ON THE IMPLEMENTED TECHNOLOGIES

customers displayed in Table I. We now aim at investigating for different scenarios the outcome of the game on technologies. As in the previous section, we consider a zone (typical of France) covered by a single base station, for a period of one month. Estimated infrastructure plus license costs, if any, will therefore be divided by the approximately $10^{4}$ zones in France and by the duration in months of the license rights. Let $c_{i, t}$ be the per zone and per month cost at provider $i$ for technology $t$. The total technological cost at each provider is assumed additive, that is the cost total cost of provider $i$ is $c_{i, \mathcal{S}_{i}}=\sum_{t \in \mathcal{S}_{i}} c_{i, t}$. This yields a cost matrix $\left(\left(c_{1, \mathcal{S}_{1}}, c_{2, \mathcal{S}_{2}}\right)\right)_{\mathcal{S}_{1}, \mathcal{S}_{2} \subset \mathcal{T}}$. Subtracting it to the revenue matrix of Table I, we get a net benefits (or utility) matrix that can be analyzed to determine if there is a Nash equilibrium at this largest time scale.

\section{A. Symmetric game}

For this first real-life scenario, we consider two incoming providers with symmetric costs. We assume the following costs: 3G license for 10 years of $649 \mathrm{M} €$ [17], and infrastructure cost of $1.4 \mathrm{~B} €[18]$. The license cost (resp. the infrastructure cost) is then evaluated to $541 €$ (resp. $1167 €$ ) per month and per zone, giving $c_{1,3 \mathrm{G}}=c_{2,3 \mathrm{G}}=1708 €$. We also assume that a license costs $649 \mathrm{M} €$ for WiMAX and the infrastructure costs $340 \mathrm{M} €$ [19], yielding $c_{1 \text {,WiMAX }}=$ $c_{2 \text {,WiMAX }}=541+283=824 €$. We assume that every access point is renewed each year and is bought at the average price of $600 €$. As no license purchase is necessary for the WiFi [20], we get then $c_{1, \mathrm{WiFi}}=c_{2, \mathrm{WiFi}}=50 €$.

In that case, we can remark that there exists again two Nash equilibria, (\{WiFi,WiMAX $\},\{$ WiMAX $\})$ and ( $\{$ WiMAX $\},\{$ WiFi,WiMAX $\})$. With respect to the previous situation, 3G is actually too expensive with the proposed license cost to be implemented.

\section{B. A WiFi-positionned provider against a $3 G$ one}

Consider provider 1 as already installed in the Internet and WiFi (basically like the provider called Free in France), and wishing to extend its position, against a 3G-installed provider 2 (Bouygues Telecom for instance). WiMAX costs are assumed to be the same as in the previous subsection, this technology being a new one. Bouygues Telecom already owning an infrastructure, only its license cost of $649 \mathrm{M} €$ accounts, giving $c_{2,3 \mathrm{G}}=541 €$. The cost of the fourth license in France is fixed to $240 \mathrm{M} €$ [17], and of the new infrastructure estimated at 1.0 $\mathrm{B} €[18]$, so that $c_{1,3 \mathrm{G}}=1033 €$ per month and per site. For $\mathrm{WiFi}$, we choose $c_{1, \mathrm{WiFi}}=0 €$ and $c_{2}$, WiFi $=50 €$ to illustrate the better position of provider 1 . The benefits matrix is given in Table II, with again best responses highlighted in bold. For this game, there are two non symetric Nash equilibria. The first one is $(\{\mathrm{WiFi}, \mathrm{WiMAX}\},\{3 \mathrm{G}, \mathrm{WiMAX}\})$. Indeed, each operator chooses the technology on which it is already present, and additionally goes to the new WiMAX technology. The second Nash equilibrium is ( $\{$ WiMAX $\},\{$ WiFi, $3 \mathrm{G}$, WiMAX $\}$ ) and corresponds to a situation where operator 2 proposes all technologies and operator 1 only proposes the WiMAX technology. Again, it is better not to fight on (the low-cost) WiFi. To have a Nash equilibrium with $3 \mathrm{G}$ implemented by provider 1 , then the cost $c_{1,3 \mathrm{G}}$ has to be reduced to $900 €$, which would mean a license fee of $67 €$ (or equivalently a global 3G license selling price of $80 \mathrm{M} €$ ). In that case, the situation $(\{3 \mathrm{G}, \mathrm{WiMAX}\},\{\mathrm{WiFi}, 3 \mathrm{G}, \mathrm{WiMAX}\})$ would be a Nash equilibrium of the technological game: provider 1 would focus on licensed technologies, giving up on WiFi. On the other hand, if the monthly cost per site for $3 \mathrm{G}$ gets as low as $694 €$, then provider 1 could keep operating WiFi, since the situation ( $\{\mathrm{WiFi}, 3 \mathrm{G}, \mathrm{WiMAX}\},\{3 \mathrm{G}, \mathrm{WiMAX}\})$ would arise as a technological Nash equilibrium.

\section{A single technology-positionned provider against a domi-} nant one

This would for instance correspond in France to Free (strongly established in the Internet and WiFi networks), named provider 1 again, against Orange, named provider 2, already positionned on almost all technologies, except WiMAX, for which we keep the costs of previous subsections. The 3G costs are also considered the same as in the previous subsection, but WiFi costs are here the same, $c_{1, \mathrm{WiFi}}=c_{2, \mathrm{WiFi}}=0 €$ due to the presence of both providers on this technology. The results are displayed in Table III. One can see here that, again, two Nash equilibria exist and are similar to those of the previous game in part V-B. That is, the existence of the WiFi infrastructure for the provider 2 plays does not affect the Nash equilibria. Hence, we deduce that the impact of the WiFi infrastructure cost is negligible compared to the $3 \mathrm{G}$ and WiMAX license and infrastructure costs. As in the previous subsection, some conditions on the license fees can be derived for $3 \mathrm{G}$ to be deployed by operators at a Nash equilibrium. 


\begin{tabular}{|c|c|c|c|c|c|c|c|c|}
\hline $1 \mathrm{I}$ & $\emptyset$ & $3 \mathrm{G}$ & WiMAX & $3 \mathrm{G}, \mathrm{WiMAX}$ & WiFi & WiFi,3G & WiFi,WiMAX & WiFi,3G,WiMAX \\
\hline$\emptyset$ & $0 ; 0$ & $0 ; 1929$ & $0 ; 2555$ & $0 ; 3716$ & $0 ; 2178$ & $0 ; 3629$ & $0 ; 4047$ & $0 ; \mathbf{4 7 7 8}$ \\
\hline 3G & $1437 ; 0$ & $1167 ; 1679$ & $1057 ; 2198$ & $810 ; 3141$ & $1208 ; 1935$ & $937 ; 3161$ & $826 ; 3493$ & $590 ; \mathbf{4 0 0 0}$ \\
\hline WiMAX & $2555 ; 0$ & $2198 ; 1549$ & $2040 ; 2040$ & $1665 ; 2875$ & $2237 ; 1837$ & $1865 ; 2954$ & $1708 ; 3238$ & $\mathbf{1 3 6 8} ; \mathbf{3 6 2 8}$ \\
\hline 3G,WiMAX & $3224 ; 0$ & $2649 ; 1302$ & $2383 ; 1665$ & $1781 ; 2273$ & $\mathbf{2 7 1 5} ; 1616$ & $\mathbf{2 1 0 0} ; 2488$ & $\mathbf{1 8 3 4} ; 2664$ & $1235 ; \mathbf{2 8 1 7}$ \\
\hline WiFi & $2228 ; 0$ & $1985 ; 1700$ & $1887 ; 2237$ & $1666 ; \mathbf{3 2 0 7}$ & $0 ;-50$ & $0 ;-591$ & $0 ;-874$ & $0 ;-1415$ \\
\hline WiFi,3G & $3187 ; 0$ & $2719 ; 1429$ & $2512 ; 1865$ & $2046 ; 2592$ & $-1033 ;-50$ & $-1033 ;-591$ & $-1033 ;-874$ & $-1033 ;-1415$ \\
\hline WiFi,WiMAX & $4097 ; 0$ & $3543 ; 1318$ & $\mathbf{3 2 8 8} ; 1708$ & $\mathbf{2 7 1 4} ; \mathbf{2 3 2 6}$ & $-824 ;-50$ & $-824 ;-591$ & $-824 ;-874$ & $-824 ;-1415$ \\
\hline WiFi,3G,WiMAX & $\mathbf{4 3 3 6} ; 0$ & $\mathbf{3 5 5 8} ; 1082$ & $3186 ; 1368$ & $2375 ; \mathbf{1 7 2 7}$ & $-1857 ;-50$ & $-1857 ;-591$ & $-1857 ;-874$ & $-1857 ;-1415$ \\
\hline
\end{tabular}

TABLE II

BENEFITS MATRIX FOR THE WIFI-3G GAME

\begin{tabular}{|c|c|c|c|c|c|c|c|c|}
\hline 112 & $\emptyset$ & $3 \mathrm{G}$ & WiMAX & 3G,WiMAX & WiFi & WiFi,3G & WiFi,WiMAX & WiFi,3G,WiMAX \\
\hline$\emptyset$ & $0 ; 0$ & $0 ; 1929$ & $0 ; 2555$ & $0 ; 3716$ & $0 ; 2228$ & $0 ; 3679$ & $0 ; 4097$ & $0 ; \mathbf{4 8 2 8}$ \\
\hline 3G & $1437 ; 0$ & $1167 ; 1679$ & $1057 ; 2198$ & $810 ; 3141$ & $1208 ; 1985$ & $937 ; 3211$ & $826 ; 3543$ & $590 ; \mathbf{4 0 5 0}$ \\
\hline WiMAX & $2555 ; 0$ & $2198 ; 1549$ & $2040 ; 2040$ & $1665 ; 2875$ & $2237 ; 1887$ & $1865 ; 3004$ & $1708 ; 3288$ & $\mathbf{1 3 6 8} ; \mathbf{3 6 7 8}$ \\
\hline 3G,WiMAX & $3224 ; 0$ & $2649 ; 1302$ & $2383 ; 1665$ & $1781 ; 2273$ & $\mathbf{2 7 1 5} ; 1666$ & $\mathbf{2 1 0 0} ; 2538$ & $\mathbf{1 8 3 4} ; 2714$ & $1235 ; \mathbf{2 8 6 7}$ \\
\hline WiFi & $2228 ; 0$ & $1985 ; 1700$ & $1887 ; 2237$ & $1666 ; \mathbf{3 2 0 7}$ & $0 ; 0$ & $0 ;-541$ & $0 ;-824$ & $0 ;-1365$ \\
\hline WiFi,3G & $3187 ; 0$ & $2719 ; 1429$ & $2512 ; 1865$ & $2046 ; 2592$ & $-1033 ; 0$ & $-1033 ;-541$ & $-1033 ;-824$ & $-1033 ;-1365$ \\
\hline WiFi,WiMAX & $4097 ; 0$ & $3543 ; 1318$ & $\mathbf{3 2 8 8} ; 1708$ & $\mathbf{2 7 1 4 ; 2 3 2 6}$ & $-824 ; 0$ & $-824 ;-541$ & $-824 ;-824$ & $-824 ;-1365$ \\
\hline WiFi,3G,WiMAX & $\mathbf{4 3 3 6} ; 0$ & $\mathbf{3 5 5 8} ; 1082$ & $3186 ; 1368$ & $2375 ; \mathbf{1 7 2 7}$ & $-1857 ; 0$ & $-1857 ;-541$ & $-1857 ;-824$ & $-1857 ;-1365$ \\
\hline
\end{tabular}

TABLE III

BENEFITS MATRIX FOR THE WIFI-DOMINANT GAME

\section{CONCLUSiOns}

We have proposed a 3-stage model to study competition among telecommunication providers. Providers have two strategic decisions to make (namely, the price they sell the service and the set of technologies to operate) on different time scales, while users react to those decisions.

The model provides some insights about the conditions under which a technology can be chosen by providers. Through some numerical computations, we highlighted that regulatory decisions such as license fees can strongly affect the outcome of the noncooperative interaction among providers.

Future work could focus on those regulatory issues, and possibly exhibit some specific regulatory decisions which would favor the development of some given technologies in a country.

\section{ACKNOWLEDGMENT}

This work was supported by Euro-NF Network of Excellence and the French research agency through the CAPTURES project.

\section{REFERENCES}

[1] IEEE 802.16-2004, IEEE Standard for Local and Metropolitan Area Networks - Part 16: Air Interface for Fixed Broadband Wireless Access Systems, October 2004

[2] J. Wardrop, "Some theoretical aspects of road traffic research," Proc. of the Institute of Civil Engineers, vol. 1, pp. 325-378, 1952.

[3] M. Osborne and A. Rubenstein, A Course on Game Theory. MIT Press, 1994.

[4] D. Acemoglu and A. Ozdaglar, "Competition and efficiency in congested markets," Mathematics of Operations Research, 2006.

[5] F. Bernstein and A. Federgruen, "A general equilibrium model for industries with price and service competition," Management Science, vol. 52, no. 6, pp. 868-886, 2004.
[6] P. Maillé and B. Tuffin, "Analysis of price competition in a slotted resource allocation game," in Proc. of IEEE INFOCOM 2008, Phoenix, AZ, USA, April 2008.

[7] _ - "Price war with partial spectrum sharing for competitive wireless service providers," in Proceedings of IEEE Globecom, December 2009.

[8] M. Manshaei, J. Freudiger, M. Felegyhazi, P. Marbach, and J.-P. Hubaux, "On wireless social community networks," in Proc. of IEEE INFOCOM, Phoenix, AZ, USA, Apr 2008.

[9] Y. Xing, R. Chandramouli, and C. Cordeiro, "Price dynamics in competitive agile spectrum access markets," Selected Areas in Communications, IEEE Journal on, vol. 25, no. 3, pp. 613-621, April 2007.

[10] P. Njoroge, A. Ozdaglar, N. Stier-Moses, and G. Weintraub, "Competition, market coverage, and quality choice in interconnected platforms," in Proceedings of the Workshop on the Economics of Networked Systems (NetEcon), 2009.

[11] M. Beckmann, C. B. McGuire, and C. B. Winsten, Studies in the economics of transportation. Yale University Press, New Heaven, Connecticut, 1956.

[12] H. Z. Aashtiani and T. L. Magnanti, "Equilibria on a congested transportation network," SIAM Journal of Algebraic and Discrete Methods, vol. 2, pp. 213-226, 1981.

[13] T. Roughgarden, Selfish Routing and the Price of Anarchy. MIT Press, 2005.

[14] 01NetPro, "Le débit sur le réseau $3 \mathrm{G}$ d'Orange passe à $14 \mathrm{mb} / \mathrm{s}$," January 2010 , http://pro.01net.com/editorial/511553/le-debit-sur-le-reseau3g-dorange-passe-a-14-mbits-s/.

[15] W. design mag, "WiMax 101 : the Evolution of WiMax," 2010, http://www.wirelessdesignmag.com.

[16] Wikipédia, "WiFi," http://fr.wikipedia.org/wiki/Wi-Fi.

[17] Mobinaute, "4ème licence 3G : Orange fait pression auprès $\mathrm{du}$ gouvernement pour ralentir son attribution," October 2009, http://www.mobinaute.com/304016-4eme-licence-3g-orange-pressionaupres-gouvernement-ralentir-attribution.html.

[18] Capital, "Mobiles : comment Free compte faire baisser les prix," May 2009, http://www.capital.fr/enquetes/strategie/mobiles-commentfree-compte-faire-baisser-les-prix-380294.

[19] Wimaxday, "Worldmax launches mobile WiMax network," June 2008, http://www.wimaxday.net/site/2008/06/17/worldmax-launches-mobilewimax-network.

[20] 01NetPro, "Le Wi-Fi devient officiellement une activité commerciale," May 2007, http://pro.01net.com/editorial/348616/le-wi-fi-devientofficiellement-une-activite-commerciale/. 